\title{
Neoextrativismo e projetos hidrelétricos em Rondônia: desdobramentos territoriais e seu significado político-institucional
}

\begin{abstract}
Neoextrativism and hydroeletric project in Rondônia: territorial developments and their political-institutional significance
\end{abstract}

\section{Neiva Araujo}

Brasil. Universidade Federal de Rondônia. Professora Adjunta na Universidade Federal de Rondônia, Doutora em Desenvolvimento Regional \& Meio Ambiente. ID ORCID: https://orcid.org/ 0000-0003-3252-4514. E-mail: neiva.araujo@unir.br. Colaboração: Pesquisa bibliográfica, análise de dados, redação e revisão.

\section{Luis Fernando Novoa Garzon}

Brasil. Universidade Federal de Rondônia. Professor Adjunto na Universidade Federal de Rondônia, Doutor em Planejamento Urbano e Regional. ID ORCID: https://orcid.org/0000-0003-2280-7959. E-mail: l.novoa@unir.br. Colaboração: Pesquisa bibliográfica, análise de dados, redação e revisão.

\section{Resumo}

O texto aborda a apropriação regulamentada de riquezas na Amazônia brasileira, com destaque para Rondônia, a partir da construção de pequenos e grandes empreendimentos hidrelétricos. Sob a retrospectiva da construção desses empreendimentos e da análise dos efeitos irreversíveis por eles gerados, são traçadas ponderações sobre as lições aprendidas e não aprendidas e possíveis desdobramentos que serão gerados com a construção da Usina Hidrelétrica (UHE) Tabajara, prevista para iniciar em 2020. Serão expostas reflexões quanto aos papéis desempenhados pelos atores (com ênfase às atuações do Ministério Público e do Judiciário) que compõem a complexa teia de relações nesses processos que indicam o avanço do capital, refletindo sobre como há um sentido neoextrativista na imposição de todos os ônus às comunidades tradicionais e na definição dos territórios locais como zonas de sacrifício. Este trabalho reflete pesquisas e atuações dos autores em Rondônia por mais de uma década, trazendo à discussão análises do Estudo de Impacto Ambiental e do Relatório de Impacto Ambiental da 
UHE Tabajara, relatos coletados junto às populações que foram ou serão afetadas, bem como verificação de processos relacionados ao Complexo do Madeira que tramitam na Justiça Estadual de Rondônia desde 2014. Esses elementos servem para analisar o passado, pensar o futuro e subsidiar discussões quanto à UHE Tabajara, projeto dado como certo em um momento em que se põe em xeque o arcabouço protetivo ambiental e em que diversos retrocessos ambientais e perseguições a ativistas ambientais na Amazônia passam a ser um fato corriqueiro.

Palavras-chave: Amazônia, Desregulamentação, Hidrelétricas, Neoextrativismo, Rondônia.

\section{Abstract}

The paper is about the regulated appropriation of wealth in the Brazilian Amazon, with emphasis on Rondônia, with focus on Rondônia, based on the construction of small and large hydroelectric projects. Analyzing the retrospective involving the construction of these undertakings and the analysis of the negative impacts generated by them, we do considerations about the lessons learned and possible developments that will be generated with the construction of the UHE Tabajara, which should start in 2020. Reflections on the roles played by the actors (with emphasis on the actions of the Public Prosecutor and the Judiciary) that make up the complex relationships in these processes that indicate the advance of capital, reflecting on how neo-extraction is used to impose burdens on traditional populations and to bring misery to local territories. This work reflects research and actions by the authors in Rondônia for more than one decade, bringing to the discussion EIS analyzes, reports collected from the populations that were or will be impacted, as well as analysis of lawsuits to involving the Madeira Complex and the floods in Porto Velho since 2014. These elements serve to analyze the past, think about the future and support discussions about the UHE Tabajara, in a delicate moment of environmental setbacks in Brazil and violence against environmental activists in the Brazilian Amazon.

Keywords: Amazon, deregulation, hydropower dams, neo-extrativism, Rondônia. 


\section{INTRODUÇÃO}

A retomada nas últimas três décadas da estratégia neocolonial e primarizadora do país na contramão de todos esforços de diversificar e densificar suas cadeias produtivas, a despeito das variações governamentais no período, constitui o sentido do neoextrativismo reinante (CASTRO, ALONSO, NASCIMENTO, 2016). O resultado é uma economia reflexa em termos de escala de intensividade na extração e escoamento de matérias-primas e uma institucionalidade maleável ao ponto de expor a população e o meio ambiente a catástrofes em série.

Um capitalismo fundado na espoliação permanente ou no estabelecimento de novas formas de acumulação primitiva (OLIVEIRA, 2003; BRANDÃO, 2010) propicia a rotinização de catástrofes sociais e ambientais produzidas por grandes projetos agrícolas, minerais e de infraestrutura. Em meio à tabula rasa da desindustrialização promovida nos anos 1990, via câmbio e liberalização comercial, restaram os estoques de recursos naturais demandados pelas chamadas "cadeias globais de valor" samento de recursos naturais (soja, gado, minério de ferro, celulose, etanol, siderurgia, metalurgia, petroquímica, cimento etc.) são expandidas no Brasil como uma derivação de acordos setoriais privados em escala global, contando com pleno suporte político-institucional interno para tanto.

A perplexidade das burocracias e segmentos sociais dedicados às mediações entre o público e o privado diante da obsolescência de seu papel é o substrato de uma estratégia teórico-política defensivista que procura circunscrever a crise estrutural do capitalismo a uma crise do chamado Welfare State ou do Estado Desenvolvimentista, ou, no limite, a uma crise da democracia. Essa postura imobilizadora pressupõe que em momentos anteriores fôssemos regidos por regimes de acumulação organizados, democráticos e virtuosos.

No caso brasileiro qual poderia ser o poder regulatório de uma sociedade política correspondente a uma sociedade econômica fundada em um

Termo utilizado por operadores de mercado para dissimular dinâmicas de reprodução ampliada de oligopólios capitalistas em disputa e/ou em composição. 
modelo neoextrativista que sintetiza biomas e modos de vida neles fundados? Condições econômicas referentes ao controle transnacional e financeiro da riqueza e condições políticas referentes à dilapidação da força social organizada e ao esvaziamento das instituições representativas possibilitaram a convergência e a articulação entre uma agenda ultraliberal à economia e uma agenda neofascista de militarização dos territórios e de controle da conduta.

A apropriação regulamentar de tantas riquezas territorializadas (águas, terras, subsolo, florestas, redes urbanas e malhas de infraestrutura) não poderia se viabilizar sem um consorciamento multiescalar entre capitais e agências públicas e semipúblicas; no caso, o Estado brasileiro em suas três instâncias e níveis. Os desastres socioambientais derivados desse modelo não são, portanto, eventos isolados. O que está em questão é a criação autolegitimada de dispositivos perpetradores de genocídios e de ecocídios continuados. Não se trata aqui de eventos isolados, mas de um método que reorganiza os processos produtivos sob impulso da máxima rentabilização apelando para a sintetização de povos e territórios na forma de custos e riscos financeiros.

A Amazônia é região prioritária para o aprofundamento desse regime de acumulação. O desmonte do licenciamento ambiental, além de medidas de regularização da grilagem e o subsequente sucateamento dos órgãos de controle e de fiscalização têm por objeto a dilatação das fronteiras de acumulação na região.

A partir de Rondônia - marcada por reincidentes ciclos exploratórios (ARAUJO, MORET, 2016; NOVOA GARZON, 2017) - e especificamente pelo grande negócio barrageiro, é possível traçar um painel do método de incorporação dos rios amazônicos e inquirir os sentidos do neoextrativismo e dos processos de desregulação que o acompanham.

\section{MATERIAIS E MÉTODOS}

O desenrolar da construção do Complexo do Madeira (anúncio das obras, processos de licenciamento, construção e operação) mistura-se às trajetórias 
pessoais e acadêmicas dos autores deste artigo. O segundo provindo das assessorias dos movimentos sociais, antes de se vincular à docência universitária, procurava interrogar o significado da privatização do rio Madeira (RO) e de seus usos sociais, desde 2005. Nesse contexto assessorou as missões da Plataforma de Direitos Humanos, Econômicos, Sociais, Ambientais e Culturais (DHESCA) envolvendo os conflitos ambientais na região do rio Madeira em 2007 e 2011.

A primeira autora, uma outsider, vinda do estado brasileiro que criou o Movimento dos Atingidos por Barragens (MAB), chega a Rondônia em plena fase de construção do Complexo do Madeira e acompanha a distância, no exercício da docência, as rebeliões de trabalhadores que, literalmente, incendiaram Porto Velho, envolvendo-se academicamente ${ }^{2}$ na sequência e vindo a conhecer de perto a realidade das famílias que perderam suas fontes de sustento e lazer com a realocação, que vivenciaram a violência à sua volta, experimentaram a instabilidade de um estilo de vida que pouco ou nada lembrava o seu modo de vida e experimentaram os impactos das Cheias do Madeira em 2014. Não bastasse uma série de promessas não cumpridas, já que o Complexo do Madeira prometia crescimento econômico, os impactados experimentam derrotas no Judiciário que deveria tratar todos com igualdade, mas que pende a um lado da balança e avaliza violências ${ }^{3}$.

O caminho dos autores cruza-se a partir de discussões relativas ao Complexo do Madeira e aproxima-se com o avanço do licenciamento ambiental da Usina Hidrelétrica (UHE) Tabajara, em Machadinho D’Oeste (RO), onde a primeira autora realizou sua pesquisa de campo durante o doutorado.

\footnotetext{
A evolução desse processo é resultado do esforço acadêmico de diferentes frentes e espaços geográficos rondonienses. Dentre eventos organizados, destaca-se o Seminário para Debater os Impactos de Pequenas Centrais Hidrelétricas (PCH), encabeçado pelo curso de Engenharia Ambiental em 2017, que contou com a participação de comunidades indígenas, do Ministério Público Federal e de docentes de diferentes áreas do conhecimento. A teia de relações e de atores que estudam ou vivem os impactos dos projetos hidrelétricos em Rondônia ganhou novo desdobramento com os objetivos traçados durante o Seminário de Planejamento e execução do projeto Nenhuma hidrelétrica a mais na Amazônia, pelo direito à vida, contra as barragens, em fevereiro de 2020.

3 O Judiciário mostra descaso inclusive ao proferir sentença sem ler qualquer pedido formulado pela família impactada, como ocorreu no processo $n^{\circ}$ 7004376-64.2018.8.22.0009, da $1^{\text {a }}$ Vara Cível de Porto Velho (RONDÔNIA, 2018). Possivelmente a petição inicial, peça que se correlaciona à sentença, não deve ter sido escaneada na migração do processo físico ao eletrônico. Tal erro é grosseiro e demonstra que o juiz Jorge Luiz dos Santos Leal sequer leu o que era postulado, indicando que "juiz neutro", na prática, se mostra indiferente ao sofrimento daqueles que perderam tudo, incluindo o seu modo de vida e a sua fonte de alimento.
} 
Este artigo é resultado de esforços individuais e de discussões coletivas ocorridas ao longo de mais de uma década, fruto de histórias ouvidas em diferentes momentos, lugares e pessoas. Os dados e as informações aqui descritos foram coletados e analisados (por meio de Estudo de Impacto Ambiental (EIA) do Complexo do Madeira e ações judiciais em tramitação na Justiça Estadual de Rondônia que questionam impactos gerados pelo Complexo do Madeira) ao longo desse processo histórico de resistência, seja na academia, seja nos movimentos sociais e até mesmo na junção de forças de diferentes grupos, o que possibilitou uma aproximação com o Ministério Público Estadual (MPE) e o Ministério Público Federal (MPF). Ao longo desses anos também foi realizada extensa pesquisa bibliográfica e documental, a partir da qual procedeu-se uma leitura crítica das experiências vividas pelas populações impactadas em Rondônia ao longo das últimas décadas. A gama de materiais utilizados no texto reflete as diferentes e complementares áreas de formação dos autores.

\section{A SAGA DOS DESASTRES HIDRELÉTRICOS EM RONDÔNIA}

A construção de empreendimentos hidrelétricos na Amazônia, iniciada nos anos 1960, tomou novo impulso nos anos 2000, com grandes e pequenos projetos, articulados entre si. Em meio às propostas de flexibilização do licenciamento ambiental e da exploração compulsória de recursos naturais em terras indígenas, faz-se necessário aquilatar o papel dos projetos hidrelétricos no aprofundamento do padrão neoextrativista de limpeza social e territorial. Considerando o uso intensivo de tecnologias e de dispositivos administrativos e simbólicos para a conversão de multivariados territórios hidrossociais (HOOGESTEGER \& VERZIJL, 2015) em províncias hidrelétricas exploradas tal qual inventariadas, pode-se afirmar que o neoextrativismo hidrelétrico pouco se distingue do mineral e produz efeitos-derrame (GUDYNAS, 2015) $^{2}$

${ }_{4}$ Efeitos sociais, ambientais e territoriais que, além de se interligarem e transbordarem uns nos outros, condicionam as instituições para que naturalizem e administrem tais efeitos. 
ainda mais desastrosos. A negação dos lugares entrelaçados de forma extra-mercantil e a adesão implícita e automática aos territórios recriados em moldes empresariais implica em perdas prévias de inteligibilidade territorial. Segundo Acselrad (2014, p. 92) é através de formas sociais reorganizadas que "o movimento dos investimentos incute a norma - os atributos disciplinares que justificam a localização e o perfil dos negócios”.

O século XXI transcorre e a Amazônia segue sendo vista como um espaço-reserva para a realização de ganhos extraordinários, refletindo a continuidade da política expansionista iniciada no final dos anos 1960 (MORETTO et al., 2012). Já no final dos anos 1980 era possível dimensionar, de forma mais alongada e consubstanciada, o significado dos Grandes Projetos. Lins Ribeiro (1988) considerava que projetos de larga escala ofereciam uma unidade de análise muito apropriada para a exploração etnográfica das intersecções espaciais, das dinâmicas populacionais e especificamente da mão de obra requerida e dos desequilíbrios de poder instaurados.

Um grande projeto, por sua larga escala de interpenetrações, é sempre um início e um fim de um arranjo territorial dado, como se fora uma tradução espacial de um complexo acúmulo de forças sociais em luta, sendo que o nível de "consórcio" é que define o centro de gravidade política, por definição assimétrica, coercitiva e inapelável. Dependendo da "consorciação", fica sob sua jurisdição a política ambiental, a política fundiária - e, de quebra, a indígena, a social, a territorial. Grandes Projetos de Investimentos (GPI), como conceituam Vainer e Araújo (1992), ao gerarem espaços em função da máxima eficácia dos investimentos aportados neles, não poderiam deixar de planejar e gerir esses mesmos espaços. Instrumentalidade territorial realçada após as reformas privatistas no setor e pelo processo objetivo de privatização e conglomeração do setor elétrico.

O balanço dos processos de licenciamento ambiental de grandes e pequenas hidrelétricas em Rondônia aponta para seu caráter protocolar e quando muito corretivo, sendo cabível como instrumento de adequação e legitimação de projetos considerados de forma genérica como estratégicos para o estado e o país, tidos, portanto, como impostergáveis (SCOTT, 2012). 
Os estudos ambientais que balizaram esses licenciamentos passaram ao largo das complexidades intrínsecas aos ecossistemas amazônicos e suas culturas entrelaçadas. $\mathrm{O}$ caminho ficou assim livre para a desfiguração de territorialidades singulares sob a forma de um esquadro de "impactos", como se houvesse de antemão suporte e capacidade de absorção deles. Determinada a plasticidade espacial da área receptora dos projetos, resta a gestão biopolítica da distribuição ou atenuação dos danos colaterais de negócios já consumados. Sevá (2005) destacava a anomalia ambiental e social de rios barrados em que são instauradas dinâmicas socioterritoriais submetidas a transformações qualitativas radicais e irreversíveis. Incorporar de forma acrítica a acepção de impactos e de seus parâmetros pré-estabelecidos significa avalizar e participar do jogo de buscar "menores impactos" ou as "maiores mitigações e compensações", jogo que só faz sentido para grupos e agentes que já estão dentro do negócio ou foram tragados por ele.

A "eletrificação" de novos rios amazônicos, inscrita no Programa de Parceria de Investimentos (PPI), é sinal de boas-vindas para investimentos incondicionados, oferta feita inicialmente para fidelizar a base econômico-política do Governo Temer (2016) e atualmente a do governo Bolsonaro, conformando arenas adicionais para a conjugação de interesses dos conglomerados privados transnacionais e das oligarquias locais-regionais. Entre os novos projetos inscritos no PPI destaca-se a UHE Tabajara, que inicialmente proposta nos anos 1980, previa dois eixos de barramento (RONDÔNIA, 2017; NÓBREGA, 2008): um em Ji-Paraná com 520 MW e outro em Tabajara com 765 MW. A proposta foi retomada em 2005, mantendo-se apenas o último barramento, com instalação de 400 MW e geração média de 237,56 MW (BRASIL, 2019).

Os processos "pré-licenciamento" apontam alterações no território do município e da região e a análise do EIA do Relatório de Impacto Ambiental (Rima) deste projeto demonstra a repetição de procedimentos conhecidos na Amazônia e no Brasil. Luzes e sombras permeiam as informações descritas no EIA da UHE Tabajara, por vezes de modo fragmentado, por vezes seguindo uma rigidez para encaixar as famílias futuramente atingidas em categorizações, mas sempre negando a ocorrência de efeitos cumulativos e sinérgicos na 
localidade, o que se evidencia com as informações relativas aos outros empreendimentos instalados na região, como as UHE Samuel e Jirau, que indicaram Machadinho D’Oeste como área indiretamente afetada em seus EIA.

A UHE Samuel foi a primeira grande hidrelétrica construída em Rondônia, nos anos 1980. Nos anos 2000, houve a construção das UHE Jirau, Santo Antônio e Rondon II ${ }^{5}$, instalada no rio Comemoração, na Bacia do rio Machado, foi inaugurada em 2011 com licenciamento concedido pela Secretaria Estadual de Meio Ambiente e tornou-se uma hidrelétrica desconhecida em Rondônia, pois foi ofuscada pelo Complexo do Madeira. Em Rondônia, dos anos 1980 até 2020 foram construídas (ou estão em fase de construção) 21 Pequenas Centrais Hidrelétricas (PCH) e 13 Centrais Geradoras Hidrelétricas (CGH), havendo a previsão de mais duas hidrelétricas na fronteira com a Bolívia, as UHE Guajará-Mirim e Cachuela Esperanza (SCG, 2020), expondo a "vocação hidrelétrica de Rondônia", expressão utilizada por intermediários políticos do empreendimento durante a audiência pública ocorrida em 2015 em Machadinho D’Oeste, para 'discutir' a UHE Tabajara.

O EIA da UHE Tabajara, em paralelismo com os estudos os empreendimentos já construídos na região, circunscreve os "impactos" nos marcos da viabilidade econômica do projeto. A projeção, feita com base em dados secundários, cria uma narrativa de que os moradores de Vila Tabajara e Dois de Novembro, áreas de maior impacto do projeto, serão "oportunizados" e não atingidos pela barragem, pois vivem em uma condição de "precariedade", suscitando questões sobre o que vem a ser desenvolvimento, a quem é dirigido e quem o dirige ${ }^{6}$. Quais os atores e os elementos que formam a cadeia de fatos dessa teia de exploração da água (e dos recursos terrritoriais) em Rondônia? As respostas passam por eventos que perpetuaram os desastres no estado (e na Amazônia).

\footnotetext{
O acesso aos dados da UHE Rondon II esbarra na não 'profissionalização' de procedimentos relacionados ao licenciamento ambiental somada à falta de disponibilização dos dados via website, o que apontam à uma falta de transparência. Não há transparência dos dados e os pedidos realizados pela Lei de Acesso à Informação foram ignorados, inviabilizando mensurar os impactos gerados por esta hidrelétrica.

6 Até mesmo os registros fotográficos de Vila Tabajara constantes no EIA induzem os leitores a pensar na condição de miserabilidade de seus moradores. Trata-se de uma narrativa desacoplada da realidade fática.
} 


\section{UHE SAMUEL}

Os conflitos agrários e a não regularização de várias áreas de terras explicam o agravamento dos conflitos sociais na região por ocasião da construção da UHE Samuel, localizada no rio Jamari, afluente do rio Madeira, no município de Candeias do Jamari, cuja obra alagou uma área de $655.599 \mathrm{~km}^{2}$ (SCG, 2020). Embora as pessoas sigam enfrentando os impactos gerados pela UHE Samuel, não há qualquer menção a eles no decorrer do tópico 5.4 (meio socioeconômico) do EIA da UHE Tabajara (IBAMA, 2019), havendo três breves menções às UHE Jirau e Santo Antônio e duas à atuação do $\mathrm{MAB}$, as quais serão posteriormente trabalhadas.

O contexto ditatorial impôs uma percepção de um desenvolvimento compulsório, priorizando a eficiência econômica em detrimento do bem-estar da população e da proteção ambiental, fenômeno que ocorreu não apenas na UHE Samuel, mas em outras hidrelétricas construídas no período (UHE Tucuruí e Balbina) (FEARNSIDE, 2005, 2015). Até o Banco Mundial, de forma indireta, precisou reconhecer ex-post estes desastres consumados como antiexemplos. A Comissão Mundial de Barragens atestou que a construção de barragens nesses moldes havia provocado impactos perenes sobre os meios de subsistência de comunidades inteiras e sobre o meio ambiente, considerando inócuos os intentos de mitigação, o que sugeria uma moratória de novos projetos. Os estudos de impacto ambiental cumpriam um papel protocolar e não influenciavam o processo decisório, cabendo às populações deslocadas a conformidade com os parcos valores indenizatórios e com as condições de realocação ofertadas (BURRIER, 2016; WCD, 2000).

Quando da tentativa de sistematizar os efeitos desastrosos causados por hidrelétricas construídas na Amazônia, tem-se que a falta de EIA, nos casos das UHE de Tucuruí e Balbina, explicitava a estratégia da ditadura empresarial-militar de invisibilizar os danos e os danificados de seus grandes projetos. Com o passar dos anos, a história oral das comunidades afetadas vai se perdendo, fazendo com que permaneça apenas a versão "oficial" .

Daí a importância redobrada de projetos como o "Memória Social dos Atingidos pela Hidrelétrica de Tucuruî", coordenado por Henri Acselrad, Sonia Maria Simões Barbosa Magalhaes Santos, Celia Regina Congilio e Maria das Graças da Silva. Conferir em https://memoriasocialtucurui.org/ 


\section{COMPLEXO DO MADEIRA}

A Bacia do rio Madeira tem uma área de $31.422,1525 \mathrm{~km}^{2}$. As UHE Jirau e Santo Antônio integram o Complexo do Madeira, que prevê a construção de mais duas hidrelétricas rio acima: i) a UHE Guajará-Mirim (também conhecida como "Cachoeira Ribeirão") no trecho binacional do rio Madeira entre Abunã e Guajará-Mirim; e a ii) UHE Cachuela Esperanza no rio Beni, na Bolívia. Os governos do Brasil e da Bolívia já acenaram para a construção da hidrelétrica binacional (BRASIL, 2018).

Apesar das radicais transformações sociais e ambientais produzidas pelo Complexo do Madeira seguirem sendo objeto de estudos e de discussões, inclusive com inúmeras ações judiciais tramitando em Rondônia, e, apesar de o EIA da UHE Tabajara ter sido revisado em 22 de novembro de 2019, percebe-se que ao longo do seu tópico 5.4 (meio socioeconômico) há apenas breves notas sobre os efeitos sinérgicos, limitando-se a três pontos de análise (IBAMA, 2019).

Primeiro, afirma que "a atuação do MAB tem sido focada nas usinas hidrelétricas de Santo Antônio e Jirau, sobretudo na questão de alterações drásticas decorrentes dos empreendimentos na atividade pesqueira, na elevação do lençol freático e no deslocamento compulsório de famílias ribeirinhas" (IBAMA, 2019, p. 71). Essa leitura minimiza a atuação do MAB na localidade e tenta criar um cenário de ausência de conflitos, o que não condiz com a realidade de Machadinho D’Oeste, foco da expansão do agronegócio e de conflitos agrários.

Segundo, menciona que a construção do Complexo do Madeira, iniciada em 2008, "com o aproveitamento de recursos ambientais da região, trouxe também a intensificação de conflitos sociais na área relativos ao uso do território e seus recursos ambientais" (IBAMA, 2019, p. 71). Contudo, tais conflitos são postos à margem da análise, ao leitor é indicado que eles existem, mas não há uma análise pormenorizada.

Terceiro, diz respeito aos conflitos trabalhistas ocorridos no Complexo do Madeira em 2011, a explicação é de que eles “ocorreram inicialmente sem a participação dos sindicatos dos trabalhadores na organização das mobilizações e nas negociações com as empresas, o que pode ter contribuído um pouco para 
a eclosão de episódios de violência" (IBAMA, 2019, p. 72). Em que pese esse artigo não ter por foco aspectos trabalhistas, cabe ponderar quanto aos efeitos do esvaziamento das leis trabalhistas após as reformas havidas desde o governo Temer. $\mathrm{O}$ argumento da ausência de sindicatos como fator detonador da rebelião de Jirau tenta culpabilizar as próprias vítimas enquanto o Consórcio da Energia Sustentável do Brasil e suas terceirizadas é que impunham regimes de trabalho análogos a campos de trabalho forçado (ZAGALLO; LISBOA, 2011). Como esperar um cenário mais favorável em relação à agudização da crise social e econômica e uma nova onda de precarização de direitos trabalhistas?

O EIA da UHE Tabajara destaca que as reivindicações dos trabalhadores do Complexo do Madeira buscavam "básicas melhorias econômicas, tais como aumento de salário e do vale alimentação, protestos contra as condições de trabalho e de alojamento" (IBAMA, 2019, p. 72). Como imaginar tais postulações em um cenário de elasticidade das relações trabalhistas? Por fim, há um destaque ao fato de que os conflitos havidos no Complexo do Madeira não se situavam na Área de Influência Indireta (AII) e que não há registros de "empreendimentos outros que tenham resultado em conflitos sociais desta natureza" (IBAMA, 2019, p. 72). Por outro lado, o Relatório Conflitos no Campo (CPT, 2020; MASSACRES..., [2011]) aponta conflitos por terra e pela água em Machadinho D’Oeste, indicando também mortes decorrentes destes conflitos e da violência no campo entre os anos de 2016 e 2017.

Cabe ponderar que no âmbito do Complexo Madeira foram inúmeros os conflitos relacionados às indenizações das famílias consideradas "diretamente afetadas". Os esclarecimentos à população não foram adequados, não houve clareza e transparência no processo indenizatório e as famílias que optaram pela carta de crédito perceberam, ao tentar comprar um novo imóvel, que o valor recebido valia pouco ante ao inflacionamento dos imóveis (INDEX..., [2020]). Moradores de Nova Mutum Paraná afirmaram que a UHE Santo Antônio pagou cerca de $\mathrm{R} \$ 100$ mil reais a título de indenização, enquanto a UHE Jirau pagou cerca de $\mathrm{R} \$ 65$ mil reais. Além de o valor ofertado pela UHE Jirau ser menor, já havia em Porto Velho o rescaldo no mercado imobiliário gerado pela UHE Santo Antônio, logo, o valor não possibilitava a compra de uma moradia similar 
àquelas que eram deixadas para trás, soma-se a falta de escritura dos imóveis, e o resultado é a invizibilização de direitos de posse e um processo de marginalização das famílias jogadas à margem da sociedade.

As hidrelétricas do Complexo do Madeira esgarçaram a legislação ambiental para que o projeto empresarial coubesse nela e não o contrário, por isso o escopo dos estudos de impacto ambiental não abrangeu a bacia hidrográfica (que é trinacional) e se limitou a uma amostragem contemplando apenas uma parte da bacia, o que atualmente coloca em xeque o EIA, inclusive com pedido de anulação dos estudos, conforme ação judicial que tramita na Justiça Federal de Porto Velho (Processo $n^{\circ}$ 0001339-57.2014.4.01.4100).

O judiciário rondoniense tem avalizado as condutas dos empreendedores, à medida que sentencia demandas em massa, muitas vezes utilizando fatos e dados que sequer constam ou têm correlação com o processo julgado, além de que há um forte entendimento no sentido de que prejuízos decorrentes da cheia histórica do rio Madeira em 2014 foram não um efeito das alterações do rio produzidas pelos reservatórios das hidrelétricas operados em cota máxima na ocasião e sim um "fato natural", muito embora o MPE tenha emitido pareceres em sentido contrário. As decisões judiciais também apontam que as pessoas e territórios que não constavam nas delimitadas áreas de impacto indicadas no EIA/Rima não podem ser indenizadas.

A conduta do judiciário é uma pequena parte do problema, já que outros atores têm participação no processo decisório atual de implementação de projetos de infraestrutura, bem como nas informações que são dadas à população impactada (quando são dadas), indicando a complexidade do problema e um jogo de interesses, pois tais projetos, apostando na chantagem locacional, são construídos em áreas de "maior privação socioeconômica e/ou habitadas por grupos sociais e étnicos sem acesso às esferas decisórias do Estado e do mercado" (ACSELRAD; MELLO; BEZERRA, 2009, p. 8-9). Além disso essas localidades tendem a ter um déficit da oferta de serviços públicos essenciais (coleta de lixo e saneamento básico), elementos que contribuem à concretização da injustiça ambiental e à consolidação de projetos neoliberais, que expropriam recursos naturais e geram pobreza e miséria. 
A Ciência, por sua vez, é instrumentalizada para afirmar aquilo que é conveniente, pois dados coletados e estudos realizados ficam retidos nas próprias empresas, possibilitando o acesso apenas da informação que passa pela censura dos empreendimentos. Outra crítica refere-se à forma como os estudos chegam ao Judiciário de modo juridicizado, na medida em que os técnicos "traduzem" a linguagem técnica ao jargão jurídico, o que pasteuriza a argumentação científica e se traduz em sentenças que dificilmente levam em conta elementos técnicos abordados ao longo do processo. Ademais, as negociações fechadas, em bloco, fazem com que o Judiciário elimine o caso a caso e, embora finalize um processo, tende a não dar cabo às insurgências que levaram os sujeitos a buscar a tutela judicial, perpetuando, assim, as lesões e violações.

\section{PEQUENAS CENTRAIS HIDRELÉTRICAS E CENTRAIS GERADORAS HIDRELÉTRICAS}

Em razão das $\mathrm{PCH}$ serem propagandeadas como de baixo impacto, os debates sobre seus efeitos encadeados têm sido negligenciados mesmo sendo seus efeitos desestruturadores similares ao verificados em grandes hidrelétricas (redução do fluxo de água nos rios; problemas à fauna de peixes; impactos ao patrimônio cultural e alterações à qualidade e temperatura da água). Mesmo nos países que obrigam a realização de Estudo de Impacto Ambiental (a exemplo da Colômbia e da Indonésia), os impactos das PCH não são considerados de modo conjunto, quando construídos diversos empreendimentos em uma mesma bacia hidrográfica (KELLY-RICHARDS et al., 2017).

Em 2016, existiam 416 usinas hidrelétricas em operação ou construção e 334 propostas ou em fase de planejamento para as bacias dos rios amazônicos, números que superam a quantia de empreendimentos das bacias do Congo e do Mekong (WINEMILLER et al., 2016). Segundo dados do Sistema de Informações de Geração (Siga) (SCG, 2020), há em operação no Brasil 731 CGH e 420 PCH, e é prevista a construção (obras iniciadas e não iniciadas) de mais 5 CGH e 158 PCH. A região norte do Brasil tem o segundo maior 
potencial para a instalação de PCH de 111,02 MW, ficando atrás apenas da região sudeste (FERREIRA et al., 2016).

As grandes hidrelétricas construídas na Amazônia e seus danos ambientais e sociais, por vezes, fazem sombra aos danos produzidos pelas pequenas hidrelétricas, como se houvesse uma hierarquia de desastres, quando na verdade todos os desastres merecem repúdio. Fato interessante é a semelhança nos ônus e nos bônus gerados com a construção de $\mathrm{PCH}$, um exemplo marcante diz respeito às $\mathrm{PCH}$ construídas na Terra Indígena Rio $\mathrm{Branco}^{8}$, pois mesmo com a geração de energia, cerca de 50\% das comunidades indígenas da localidade não possuem acesso à energia elétrica. Indígenas da localidade relataram mudanças no rio após os barramentos, incluindo a diminuição da oferta de peixes e a contaminação da água pelo aumento do uso de agrotóxicos na região. As enchentes fora de época têm ocorrido. $\mathrm{O}$ adoecimento do rio causa enfermidades, especialmente às crianças, proibidas de tomar banho no rio em razão de manchas na pele. As comunidades passaram a consumir água mineral para evitar diarreias. Os entrevistados mencionam que as mudanças mais significativas ocorreram na última década, influenciando e afetando o transporte de mercadorias e de pessoas. $\mathrm{O}$ assoreamento do rio também é uma reclamação dos indígenas, assim como a falta de transparência durante a construção das PCH (RIBEIRO, ARAUJO, ANDRADE, 2019).

Os retrocessos ambientais, anunciados e os que se consolidam, dificultam o aprofundamento de discussões quanto a "pequenos" projetos, a exemplo das $\mathrm{PCH}$, impondo a escolha das tragédias que serão trazidas à tona, o que não exime a necessidade de ampliar as discussões, em especial, porque tais empreendimentos têm efeitos sinérgicos e cumulativos e tendem a ter a sua regulação ainda mais flexibilizada no atual governo, o que pode impulsionar, ainda mais, a proliferação desse tipo de empreendimento na Amazônia brasileira.

\footnotetext{
As informações aqui contidas e relativas à Terra Indígena Rio Branco decorrem do Seminário para Debater os Impactos de Pequenas Centrais Hidrelétricas, ocorrido em 2017, e das rodas de conversa realizadas em 2019 com discentes indígenas do curso de Licenciatura em Educação Básica Intercultural, que vivem no local.
} 


\section{UHE TABAJARA: A RETOMADA DO CICLO HIDRELÉTRICO NA AMAZÔNIA OU ADIVINHE QUEM VEM PARA JANTAR}

Os Planos Decenais de Energia (PDE) 2026 e 2027 indicaram a construção da UHE Tabajara e da UHE Cachuela Esperanza no rio Beni, esta última na fronteira entre Brasil (Rondônia) e Bolívia (BRASIL, 2018). Todavia, o PDE 2029 (BRASIL, 2019) indica apenas a construção da UHE Tabajara. Portanto, embora necessária a atenção a ambos os projetos, neste momento, o projeto com maiores sinalizações dos investidores merece proporcionalmente maior monitoramento.

Problemas que circundam a construção de hidrelétricas na Amazônia estão presentes no projeto da UHE Tabajara antes do início da obra, dentre eles, destacam-se: i) falta de infraestrutura prévia no município e nas comunidades impactadas; ii) inflacionamento de preços e especulação imobiliária; iii) subdimensionamento dos impactos e dos impactados; iv) falhas no EIA; v) falta de transparência do processo; vi) e obra como capital político.

O EIA da UHE Tabajara foi disponibilizado no início de 2020, mas já em 2015 o município de Machadinho D’Oeste estimava receber com a obra cerca de 5 mil novos moradores temporários para trabalhar na obra, o que criaria um aumento populacional de cerca de $13,5 \%$, número suficiente para impactar um município com parca estrutura. A exemplo de outros EIA de projetos hidrelétricos, não houve uma análise minuciosa de uma série de elementos fáticos que permeiam a comunidade de Machadinho D’Oeste.

Na produção de uma visibilidade específica, a descrição das localidades, seus habitantes e atividades apresenta-se como artefato estrategicamente calculado, que descaracteriza as redes de relações e as histórias conformadoras de trajetórias e memórias coletivas, esvaziando o sentido de um passado compartilhado e de um destino comum [sic]. (TEIXEIRA; LASCHEFSKI; MOTTA, 2020, p. 8).

Mais uma vez fica patente a ambivalência do EIA, ante a omissão de dados e de trechos significativos da recente história de implantação de projetos de 
infraestrutura em Rondônia. Percebe-se que o EIA traz visibilidades no intuito de categorizar administrativamente os atingidos, a partir de mapas, tabelas e categorizações, assim, os estudos ambientais não analisam empreendimentos existentes e sugestionam territórios vazios e impactos socioeconômicos de menor proporção (TEIXEIRA; LASCHEFSKI; MOTTA, 2020). Essa falsa premissa reflete não apenas na discussão do projeto na fase pré-construção, mas interfere até mesmo nas fases pós-construção, pois eventuais ações judiciais podem ser desfavoráveis aos impactados, sob o argumento de que eles não constavam no EIA, o que indica a perversidade das escolhas técnicas realizadas na confecção deste instrumento que deveria servir para proteger.

$\mathrm{O}$ argumento de que os impactos são mínimos ou de que os benefícios gerados pelos megaprojetos se sobrepõem aos malefícios precisa ser analisado com cautela. Geralmente essa narrativa serve para autorizar condutas degradatórias e viabilizar o projeto, invisibilizando as pessoas impactadas, sob a justificativa de que elas terão condições de vida melhoradas. A realidade demonstra que os sujeitos costumam ser inseridos subalternamente na lógica capitalista e realocados nas periferias da cidade, privados de seus modos de vida e sem as riquezas não monetárias que possuíam.

É necessário que os impactos sejam vistos em sua transversalidade, pois seus efeitos são amplos e profundos. Conceber que os impactos se "limitam" ao deslocamento compulsório (SANTOS, 2007) é ignorar as vivências e o estilo de vida das pessoas deslocadas e, consequentemente, negar a elas direitos básicos que deveriam ser assegurados, incluindo o direito de ir e vir, que é afastado sob o pretexto do "interesse público". Comumente os estudos encobrem o fato de que o próprio empreendimento realiza as intervenções que geram os impactos e destaca "programas de redução de impactos", embora seja comum nos EIA a utilização genérica de tais programas, nem sempre explícitos quanto às medidas que serão adotadas.

Se comparada ao Complexo do Madeira, a UHE Tabajara é menor, mas isso não significa que terá mais "impactos positivos" ou "menos impactos negativos", ao contrário, até o momento a omissão de informações e falhas no EIA/Rima indicam que deve haver uma repetição dos efeitos desastrosos 
produzidos pelos outros empreendimentos hidrelétricos construídos no estado, até mesmo porque muitos dos moradores da Vila Tabajara foram deslocados para a localidade quando da construção da UHE Itaipu e mais uma vez enfrentam os mesmos dilemas, como afirmou um morador da localidade: "dizem que um raio não cai duas vezes no mesmo lugar, mas parece que às vezes cai” (Informação verbal) ${ }^{9}$. Fato é que tal raio tem caído Brasil afora, a exemplo de famílias atingidas no Pará pela UHE de Belo Monte na esteira da UHE Tucuruí, assim como os atingidos sequencialmente pelas UHE construídas no rio São Francisco e depois afetados pelas obras de transposição, fatos que indicam a itinerância dos processos espoliativos próprios ao capitalismo brasileiro.

Há diferentes números indicando a proporção de pessoas atingidas pela construção da UHE Tabajara. A empresa terceirizada contratada para fazer o levantamento socioeconômico informa em seu site que serão impactadas 464 pessoas (CADASTRO..., 2017); para a mídia local o número é de 150 pessoas impactadas (FREIRE, 2014). Todavia, há indicativos de subdimensionamento do número de impactados, que totalizam 13.297 famílias tradicionais, aproximadamente 66.485 pessoas, portanto, apenas no território rondoniense seriam 7.957 famílias impactadas (RONDÔNIA, 2017).

Além do subdimensionamento do número de atingidos, há informações que só podem ser acessadas no período das secas, a exemplo das embarcações encalhadas, porém os levantamentos realizaram-se no período das chuvas, assim, a "equipe de estudos da UHE Tabajara esteve no local procurando por tais pontos, na época da cheia, quando a maior parte deles estavam submersos. Isso ocorreu no ano de 2015. Desde então a equipe não retornou para refazer os trabalhos in loco" (RONDÔNIA, 2017, p. 67).

O Termo de Referência da UHE Tabajara falha ao separar os processos biofísicos e socioculturais, vez que não há análise integrada, o que pode gerar resultados que não correspondem à realidade. Ademais, o Termo de Referência não aborda o impacto cumulativo de hidrelétricas na mesma bacia hidrográfica,

\footnotetext{
9 Informação fornecida por um morador de Vila Tabajara (Machadinho D’Oeste-RO), que lá foi realocado em razão da construção da UHE Itaipu, durante entrevista realizada na localidade, em 24 de outubro de 2015.
} 
ignorando os projetos UHE Guajará, UHE Cachuela Esperanza, PCH Jaburu e PCH Machadinho) (RONDÔNIA, 2017).

O conceito de "atingido" é utilizado de modo restritivo, possivelmente para diminuir o número de impactados (VAINER, 2008). Tal discussão é aprofundada em Parecer Pericial elaborado, após visitas in loco, para subsidiar ações pelo MPF em relação à UHE Tabajara (RONDÔNIA, 2017). O próprio Instituto Brasileiro do Meio Ambiente e dos Recursos Naturais Renováveis (IBAMA, 2019) aponta uma série de pendências e fragilidades no EIA/Rima. Diversos itens do Termo de Referência foram apresentados de modo genérico, apenas mencionando capítulos e/ou volumes, sem indicação do número de página, inviabilizando a localização das informações. Também não foram apresentadas certidões emitidas pelos municípios da designada Área Diretamente Afetada (ADA) e houve indicação de estabilidade geológica, sem a devida comprovação. Recursos pesqueiros foram indicados, mas sem confrontação da lista de espécies. Em relação à pesca, não foram indicados os pontos de desembarque pesqueiro pelo EIA/Rima, tampouco foi indicada a evolução das espécies de peixe com valor econômico ou estimativa do consumo mensal de peixe nas localidades ribeirinhas da chamada Área de Influência Direta (AID) (RONDÔNIA, 2017).

Quanto à área indicada como Área Indiretamente Afetada (AIA), há apenas a representação em um mapa (IBAMA, 2019, p. 114). As áreas de interesse econômico não foram cadastradas na AII, apenas na AID, sendo que as áreas de interesse econômico informais não foram apontadas na AII, tampouco AID. Não ocorreu o cadastramento e o mapeamento de usuários dos recursos hídricos ou indicativo de futuras demandas ou conflitos envolvendo uso da água. Informações quanto às vazões de água são incompletas. Como se percebe, a enumeração das quadrículas espaciais segundo a gradação dos "impactos" atende aos interesses da futura gestão ambiental-territorial do rio desapossado e de seu entorno.

As falhas elencadas são exemplificativas de um método, não de meros deslizes técnicos, método que se reafirma em deformações similares encontradas em outros projetos hidrelétricos e discorridos ao longo deste trabalho. As lacunas reiteradas do EIA/Rima também abarcam uma série de itens relativos ao meio socioeconômico (IBAMA, 2019), a exemplo da indicação 
de condições gerais de educação que não foram detalhadas. Também não foi feita a caracterização dos meios de transporte (e seus fluxos) e dos meios de comunicação disponíveis (TV, rádio, jornais) em Machadinho D’Oeste. Do mesmo modo, informações quanto ao fornecimento de energia à área rural e urbana ao município não são explicitadas.

Mesmo sem ter iniciado as obras, a UHE Tabajara já impulsionou a abertura de uma série de procedimentos junto ao MPF de Rondônia e do Amazonas, inclusive, gerou questionamentos quanto à forma como elaborado o Termo de Referência (que orienta o EIA). Entre as deficiências apontadas (RONDÔNIA, 2017), destacam-se: o subdimensionamento de áreas afetadas, da população atingida e do deslocamento populacional compulsório; negação dos efeitos desestruturantes à jusante; negligência de riscos à segurança hídrica e alimentar, bem como dos riscos às comunidades tradicionais e indígenas; omissão de indígenas isolados e subdimensionamento dos custos social, ambiental e econômico do empreendimento.

O EIA/Rima da UHE Tabajara desconsiderou a possível desorganização das dinâmicas sociais e culturais por conta dos fluxos migratórios decorrentes das obras. A capacidade da infraestrutura local não foi nem dimensionada nem detalhada (água, esgotamento sanitário, coleta e destinação final dos resíduos, saúde, educação, segurança pública, defesa civil, turismo e lazer, sistema viário, transporte, comunicação). Tais lacunas são pré-condição para que futuros concessionários privados estabeleçam suas jurisdições e requisitos territoriais intransitivos, fazendo com que medidas mitigatórias e compensatórias sejam percebidas como dádivas das empresas. Os possíveis agravamentos à saúde local nas etapas de planejamento, implantação e operação da UHE Tabajara não foram mencionados. No mesmo sentido, não houve indicação da localização das unidades de saúde, tampouco considerada a (in)suficiência dos profissionais ante o aumento de demanda gerado pela obra (IBAMA, 2019).

Não consta no EIA/Rima a previsão de quaisquer programas de saúde, muito embora sejam apontados os riscos de sobrecarga do sistema disponível no município, o que há é uma menção genérica no chamado Programa de Reforço à Infraestrutura e aos Equipamentos Sociais, que "tem como objetivo apoiar o 
reforço ou melhoria da estrutura de saúde, educação e segurança de Machadinho D'Oeste. [...] Os impactos provocados pelo AHE Tabajara serão monitorados juntamente com a [parágrafo inacabado no Rima]" (IBAMA, 2019). Serão monitorados os impactos? Junto a quem, com quem? Essas e outras generalidades indicadas no EIA e no Rima denotam como são deliberadamente debilitados os instrumentos que servem de parâmetro para a construção do empreendimento.

Embora o Rima reconheça que a obra provocará "impactos negativos", limita-os à Comunidade Tabajara (o que faz crer que a Dois de Novembro não esteja no grupo, apesar de se tratar do local do barramento). Há indicação de que as pessoas serão transferidas de lugar sem qualquer informação quanto a realocação ou critérios utilizados para arbitrar os valores indenizatórios. Nos chamados impactos indiretos, aponta-se para o aumento populacional e o aumento da necessidade por serviços públicos durante a obra, não havendo, mais uma vez, detalhamento em nenhum programa de formas de minimizar os efeitos desse boom (IBAMA, 2019).

O Rima também não detalha quais seriam exatamente os impactos positivos do empreendimento, resumindo-os à geração de empregos diretos e indiretos nas obras, "o que provocaria o aquecimento da economia de Machadinho D’Oeste, beneficiando a população com empregos na obra e no comércio, além do aumento da arrecadação de impostos pela Prefeitura Municipal" (IBAMA, 2019, p. 61). Ora, inúmeros são os exemplos no Brasil e na Amazônia indicando que os provisórios e parcos "benefícios" gerados não servem como contrapeso para lidar com o caos programado que se instala na oferta de serviços públicos, de habitação, de transportes e de segurança pública, até mesmo porque esses empreendimentos costumam receber incentivos fiscais dos municípios e estados, o que não geraria a aludida arrecadação de impostos mencionada no EIA.

O Rima da UHE Tabajara prevê, em seu Programa de Compensação pelas Perdas de Terras e Deslocamento Compulsório da População, "a avaliação e a compra dos imóveis atingidos pela implantação da barragem, do lago e da Área de Preservação Permanente (APP)" (IBAMA, 2019, RIMA, p. 59). Tal programa também será responsável pela remoção ou indenização às famílias que residem "nestas" áreas, o que abrange a Vila Tabajara. Essa prática repete 
aquelas adotadas no EIA do Complexo do Madeira (IBAMA, 2015), e o resultado neste caso foi uma enxurrada de ações judiciais e de pessoas que ficaram à margem dos processos decisórios e arcaram com os prejuízos às suas custas, pois a maioria sequer teve respaldo judiciário, pois não eram contempladas no EIA.

Não há no EIA de Tabajara informação quanto aos efeitos sinérgicos da obra em relação às comunidades impactadas, nem detalhamento ou esclarecimentos dos conflitos decorrentes de outros empreendimentos na chamada AII. O EIA/Rima, seguindo o método das lacunas a serem preenchidas posteriormente sob chantagem e coação, não indica a proporção dos impactos gerados pela UHE Tabajara e a forma de compensação no que se refere aos bens públicos (sistemas de comunicação, escolas, cemitérios etc). Não há indicação das áreas de lazer e/ou turismo na AII, nem qualquer avaliação da produção (agricultura) em áreas de assentamento ou na vazante, omitindo informações quanto ao uso do rio para transporte.

Apesar de o EIA da UHE Tabajara indicar outras obras à região a exemplo da Linha de transmissão entre Jaru, Vale do Anari, Machadinho D’Oeste e Cujubim, da pavimentação da rodovia RO-257 e da construção das PCH Machadinho e Jaburu não há qualquer análise dos efeitos combinados dessas obras, destaca-se que as PCH estão previstas para a mesma bacia hidrográfica que a UHE Tabajara. O que se verifica no EIA (IBAMA, 2019, p. 61) é uma negação dessas interações desestruturantes:

Pela descrição ora apresentada pode-se afirmar que não há conflito entre os projetos de infraestrutura mencionados e o AHE Tabajara. Ao mesmo tempo, os projetos que tendem a "impactar as comunidades atingidas" pelo AHE Tabajara seriam o previstos para a vila Tabajara, onde não há nenhum projeto previsto, ou para o município de Machadinho D'Oeste. Assim, não haverá impactos desses empreendimentos sobre as comunidades atingidas pelo AHE Tabajara.

O EIA de Tabajara também aponta "rumores" de construção de um terminal graneleiro na região, contudo, por se tratar de um "rumor", não o aprofunda ao longo dos estudos. Por conta das omissões contidas no EIA, o MPF de 
Rondônia expediu uma recomendação ao Ibama, solicitando que nenhuma licença seja emitida até que restem esclarecidos onze pontos elencados, por entender que não houve o aprofundamento necessário para um empreendimento de tal porte. Inclusive, a Procuradora da República, Gisele Bleggi, destacou que o "relatório dos estudos mais se assemelha a um documento de publicidade positiva do empreendimento do que de uma avaliação de impactos, fazendo crer que os impactos são poucos e restritos à Vila Tabajara” (BOOM..., 2019).

Contudo, apesar das várias ressalvas feitas em inúmeras recomendações elaboradas pelo MPF e pelo MPE de Rondônia, "sugerindo a complementação urgente do EIA/RIMA, o IBAMA aceitou os estudos em dezembro de 2019, sem que as complementações apontadas fossem feitas, e sem o atendimento de todos os itens do Termo de Referência emitido pelo IBAMA" (MPF, 2020). Assim, a Recomendação no 02, de 25 de março de 2020 emitida pelo MPF solicitou à Aneel que não aprovasse o estudo de viabilidade da UHE Tabajara sem que o empreendedor complemente os estudos do EIA/Rima Tabajara.

O descaso às recomendações elaboradas pelo MPF e pelo MPE, indica que apesar do farto arcabouço de legislação protetiva ao meio ambiente, há uma forte atuação política e econômica que acaba ignorando premissas legais, impondo a sua vontade, despedaçando relações, histórias, comunidades e pessoas. Isso indica, na prática, a vulnerabilização do instrumento de licenciamento ambiental como procedimento padrão dos ajustes institucionais que vem na esteira dos ajustes espaciais resultantes da implementação de hidrelétricas nos rios amazônicos. Percebe-se que o surgimento e o aprimoramento da proteção ambiental não fizeram com que os rios deixassem de ser rios, não evitaram que comunidades e territórios se desencontrassem irremediavelmente. Enquanto condutas obstinadamente omissivas vão se desenrolando e se perpetuando nos estudos ambientais, eivados, assim, de vícios de origem, tragédias anunciadas vão sendo reanunciadas. Não há outra expectativa realista senão a da mobilização social para neutralizar esses projetos, a exemplo do movimento dos povos Arara e Gavião que barrou a construção da UHE Tabajara no início dos anos 1990 (NÓBREGA, 2008). 


\section{CONSIDERAÇÕES FINAIS}

Os elementos que circundam a construção de hidrelétricas em Rondônia, sejam elas de pequeno ou de grande porte, indicam um claro sentido neoextrativista, à medida que os recursos são expropriados sem que haja qualquer intento palpável de reconstituição das comunidades atingidas. A crescente tecnificação do espaço amazônico em prol de sua funcionalidade para os fluxos exportadores de commodities não admite sequer processos de transição da estrutura produtiva e das formas de organização social. O tempo vazio e acelerado simplesmente é acoplado ao espaço esvaziado de vivências e memórias anteriores, em negação de qualquer alteridade não mercantil. Exemplo singelo disso é o fato de que muitas das comunidades-sede de projetos hidrelétricos sequer têm acesso a energia elétrica.

Mesmo com um considerável arcabouço protetivo ambiental, fica clara a participação de vários atores na concretização dos empreendimentos hidrelétricos, uns agindo, como o oligopólio da indústria extrativa elétrica e as agências públicas capturadas, outros omitindo, parcial ou inteiramente, como os órgãos de controle e o Poder Judiciário. O mercado mostra-se como uma solução a problemas locais, mas à medida que os empreendimentos finalizam a etapa de construção, ele tende a atribuir a responsabilidade dos problemas criados ao Executivo que, por sua vez, menciona que não tinha condições de prever todos os impactos negativos que seriam criados e, assim, não há responsabilização nem corresponsabilização quando os desastres se consumam.

A "culpa" pelos efeitos desastrosos tende a ser atribuída aos EIA e ao licenciamento ambiental por suas eventuais falhas. Na verdade, as falhas não admitidas são as sistêmicas, como indicam as pistas inscritas tanto nos estudos quanto nas licenças ambientais, processos a partir dos quais é possível explicitar estratégias e atores envolvidos. Por isso mesmo questionamentos ao EIA/Rima tendem a ser rechaçados pelo Judiciário, o qual avaliza a continuidade da obra e quando a obra se materializa nega acesso à justiça àqueles que buscam indenizações, sob o argumento de que não há relação de causa e efeito entre os danos e os empreendimentos. O Complexo do Madeira é um indisfarçável antiexemplo 
de como sujeitos que não foram indicados no EIA, que, muito embora impactados, ficaram sem o respaldo da justiça. Ainda que amparados pela legislação ambiental, muitos dos julgamentos foram desfavoráveis, expondo lacunas entre a teoria e a prática.

Ao analisar esse processo em outros empreendimentos hidrelétricos, a exemplo de Belo Monte, tem-se que mesmo com um aparato protetivo, falta sensibilidade e aprofundamento em questões tão específicas que têm emergido na sociedade, mas que não são aprofundadas em cursos de formação ou até mesmo cobradas em concursos de ingresso ao Judiciário. Em comarcas do interior o mesmo juiz que sentencia questões envolvendo Direito de Família, crimes de pequena ou grande monta, também enfrenta ações com danos ambientais. Contudo, varas especializadas não garantem uma melhor análise, por conta das origens dos magistrados, que às vezes se envolvem com o agronegócio.

A afirmativa de que o empreendimento futuro será diferente daquele que já se materializou indica um ciclo de desastres que é avalizado por atores que deveriam impedir ou coibir atos que violem a proteção ambiental, que deveriam proteger os sujeitos historicamente vulnerabilizados. Comprovação disso é que mesmo com a atuação de diversos atores (a exemplo do Ministério Público), o Judiciário tende a proferir decisões que premiam o capital, sob o argumento da necessidade de "desenvolvimento", sem questionar a quem e a que preço esse "desenvolvimento" ocorre e se realmente ocorre.

Reconhecendo a caracterização da ocorrência, nos anos 1980, de uma "desprivatização moderada e pragmática dos espaços de uso comum" (ACSELRAD, 2004), fundada na concepção de uma legislação ambiental protetora e centralizada, como não reconhecer que, a partir dos anos 1990 até o presente, prevalece o movimento reverso, o da privatização em distintas possibilidades desses mesmos espaços comuns?

A desregulação ambiental ocorre não apenas com a alteração ou redução da legislação, como se tem buscado destacar nos últimos anos, a partir das respostas que se dão à representação do licenciamento ambiental encarnado como bode expiatório dos negócios "paralisados" no país. A desregulação se materializa pela omissão, proposital ou tácita, quando premissas que deveriam 
nortear os procedimentos são ignoradas e isso ocorre quando processos técnicos escondem escolhas políticas, seja no licenciamento, seja no julgamento de processos envolvendo violações aos direitos humanos ambientais.

\section{REFERÊNCIAS BIBLIOGRÁFICAS}

1. ACSELRAD, Henri. Disputas cognitivas e exercício da capacidade crítica: o caso dos conflitos ambientais no Brasil. Sociologias, Porto Alegre, v. 16, n. 35, p. 84-105, 2014.

2. ACSELRAD, Henri; MELLO, Cecilia Campello do Amaral; BEZERRA, Gustavo das Neves. O que é Justiça Ambiental? Rio de Janeiro: Garamond, 2009.

3. ARAUJO, Neiva Cristina de; MORET, Artur de Souza. Direitos humanos e hidrelétricas: uma análise dos impactos socioambientais e econômicos gerados em Rondônia. Veredas do Direito, Belo Horizonte, v. 13, n. 26, p. 167-194, 2016.

4. BOOM econômico da construção de hidrelétrica é passageiro; depois vem a miséria e o caos, alerta MPF para o caso Tabajara. Expressão Tabajara, Porto Velho, 14 dez. 2019. Disponível em: https://bit.ly/31cg9Id. Acesso em: 3 ago. 2020.

5. BRANDÃO, Carlos. Acumulação primitiva permanente e desenvolvimento capitalista no Brasil contemporâneo. In: ALMEIDA, Alfredo Wagner Berno de et al. Capitalismo globalizado e recursos territoriais: fronteiras da acumulação no Brasil contemporâneo. Rio de Janeiro: Lamparina, 2010. p. 39-70.

6. BRASIL. Plano decenal de expansão de energia 2027. Brasília, DF: Ministério de Minas e Energia; Empresa de Pesquisa Energética, 2018. Disponível em: https://bit.ly/39GPLKl. Acesso em: 21 jan. 2019.

7. BRASIL. Plano Decenal de Expansão de Energia 2029. Brasília, DF: Ministério de Minas e Energia; Empresa de Pesquisa Energética, 2019. Disponível em: https://bit.ly/2OWOAgc. Acesso em: 29 set. 2019.

8. BURRIER, G. The developmental state, civil society, and hydroelectric politics in Brazil. The Journal of Environment \& Development, University of CaliforniaSanta Barbara, v. 25, n. 3, p. 332-358, 2016.

9. CADASTRO socioeconômico AHE Tabajara. Comunica Tabajara, Machadinho D’Oeste, jan. 2015. Disponível em: https://bit.ly/39rK8jc. Acesso em: 3 ago. 2017.

10. CASTRO, Edna; ALONSO, Sara; NASCIMENTO, Sabrina. Mineração na PanAmazônia: neoextrativismo, colonialidade e lutas territoriais. In: ZHOURI, 
Andrea; BOLADOS, Paola; CASTRO, Edna. (org.). Mineração na América do Sul: neoextrativismo e lutas territoriais. São Paulo: Annablume, 2016. p. 155-180.

11. CPT. Conflitos no Campo. Brasil, 2019. Goiânia: CPT Nacional, 2020. Disponível em: https://bit.ly/39FcIhb. Acesso em: 6 jul. 2020.

12. MASSACRES no campo. CPT Nacional, Goiânia, [2011]. Disponível em: https://bit.ly/2BJ3zHT. Acesso em: 6 jul. 2020.

13. ZAGALLO, José Guilherme Carvalho; LISBOA, Marijane Vieira. Violações de direitos humanos nas hidrelétricas do rio Madeira: relatório preliminar de missão de monitoramento. Curitiba: Dhesca Brasil, 2011.

14. FEARNSIDE, Philip Martin. Brazil's Samuel dam: lessons for hydroelectric development policy and the environment in Amazonia. Environmental Management, Nova Iorque, v. 35, n. 92, p. 1-19, 2005.

15. FEARNSIDE, Philip Martin. Hidrelétricas na Amazônia. Manaus: Inpa, 2015. v. 2.

16. FERREIRA, Jacson Hudson Inácio; CAMACHO, José Roberto; MALAGOLI, Juliana Almansa; GUIMARÃES JÚNIOR, Sebastião Camargo. Assessment of the potential of small hydropower development in Brazil. Renewable and Sustainable Energy Reviews, Amsterdam, v. 56, p. 380-387, 2016.

17. FREIRE, Marcelo. Construção da usina de Tabajara deve gerar quase 6 mil empregos e supervalorizar a região de Machadinho do Oeste. Ariquemes Online, Porto Velho, 14 abr. 2014. Disponível em: https://bit.ly/2Eif8qr. Acesso em: 6 ago. 2017.

18. GUDYNAS, Eduardo. Extractivismos: ecologia, economía y política de un modo de entender el desarrollo y la naturaleza. Cochabamba: Cedib; Claes, 2015.

19. HOOGESTEGER, Jaime; VERZIJL, Andres. Grassroots scalar politics: Insights from peasant water struggles in the Ecuadorian and Peruvian Andes. Geoforum, Wageningen, v. 62, p. 13-23, 2015. DOI: https://doi.org/10.1016/j.geoforum.2015.03.013.

20. INDEX of /hidreleticas. Ibama, Brasília, DF, [2020]. Disponível em: https://bit.ly/2XbNORe Acesso em: 10 nov. 2015.

21. IBAMA. Licenciamento da UHE Tabajara. Brasília, DF: Ibama, 2019. Disponível em: https://bit.ly/3k2ljpt. Acesso em: 6 fev. 2020.

22. KELLY-RICHARDS, Sarah; SILBER-COATS, Noah; CROOTOF, Arica; TECKLIN, David; BAUER, Carl. Governing the transition to renewable energy: a review of impacts and policy issues in the small hydropower boom. Energy Policy, Amsterdam, v. 101, p. 251-264, 2017.

23. MORETTO, Evandro Mateus; GOMES, Carina Sernaglia; ROQUETTI, Daniel Rondinelli; JORDÃO, Carolina de Oliveira. Histórico, tendências e perspectivas no 
planejamento espacial de usinas hidrelétricas brasileiras: a antiga e atual fronteira. Ambiente \& Sociedade, São Paulo, v. 15, n. 3, p. 141-164, 2012.

24. MPF. Procuradoria da República em Rondônia. Recomendação $\mathrm{n}^{\circ} 02$, de 25 de março de 2020. Procedimento Administrativo no 1.31.000.001274/2019-11. Brasília, DF: MPF, 2020. Disponível em: https://bit.ly/2XqaLjP. Acesso em: 3 ago. 2020.

25. NÓBREGA, Renata da Silva. Contra as invasões bárbaras, a humanidade: a luta dos Arara (Karo) e dos Gavião (Ikoloehj) contra os projetos hidrelétricos do Rio Machado, em Rondônia. 2008. Dissertação (Mestrado em Sociologia, Trabalho, Cultura e Ambiente) - Unicamp, Campinas, 2008.

26. NOVOA GARZON, Luis Fernando. Grandes projetos de infraestrutura de "segunda geração" e a expansão da fronteira elétrica na Amazônia. In: HERRERA, José Antônio; CAVALVANTE, Maria Madalena de Aguiar. Hidrelétricas na Amazônia: implicações territoriais nas áreas de influência das Usinas nos rios Xingu (Pará) e Madeira (Rondônia). Belém: Gapta, 2017. p. 11-40.

27. OLIVEIRA, Francisco de. Crítica à razão dualista: o ornitorrinco. São Paulo: Boitempo, 2003.

28. RIBEIRO, Gustavo Lins. Transnational capitalism and hydropolitics in Argentina: the Yacyretá high dam. Gainesville: University Press of Florida, 1988.

29. RIBEIRO, João Gilberto de Souza; ARAUJO, Neiva; ANDRADE, Nara Luísa Reis de. Impactos socioambientais das PCHs em terra indígena na Bacia do Rio Branco, Rondônia. In: CARAMELLO, Nubia; STACHIW, Rosalvo; QUADROS, Kenia; FERRONATO, Marcelo (org.). Amazônia contribuição científica para gestão hídrica. Ituiutaba: Barlavento, 2019. p. 417-438.

30. RONDÔNIA. Parecer Pericial 02/2017/SPJPR/CRP4/SEAP/MPF. Ji-Paraná: Procuradoria da República no Estado de Rondônia, 2017. Disponível em: https://bit.ly/30VnT12. Acesso em: 25 jul. 2020.

31. RONDÔNIA. Processo $n^{\circ}$ 7004376-64.2018.8.22.0009. Recorrente: Maria Lucilene Alves de Lima. Recorrido: Vera Lucia Silva e outros. Diário de Justiça, Rondônia, p. 363. 25 out. 2018. Disponível em: https://bit.ly/3fofv5z. Acesso em: 24 jul. 2020.

32. SANTOS, Sonia Maria Simões Barbosa Magalhães. Lamento e dor: uma análise sócio-antropológica do deslocamento compulsório provocado pela construção de barragens. 2007. Tese (Doutorado) - Universidade Federal do Pará, Instituto de Filosofia e Ciências Humanas, Belém, 2007.

33. SCG. Sistema de Informações de Geração da Aneel: Siga. Aneel, Brasília, DF, 3 abr. 2020, 15:04. Disponível em: https://bit.ly/3eT31MV. Acesso em: 8 jun. 2020.

34. SCOTT, Parry. Descaso planejado: uma interpretação de projetos de barragem a partir da experiência da UHE Itaparica no rio São Francisco. In: ZHOURI, A. (org.). 
Desenvolvimento, reconhecimento de direitos e conflitos territoriais. Brasília, DF: ABA, 2012. p. 122-146.

35. SEVÁ FILHO, Arsênio Oswaldo. Oswaldo. Conhecimento crítico das mega hidrelétricas: para avaliar de outro modo alterações naturais, transformações sociais e a destruição dos monumentos fluviais. In: SEVÁ FILHO, Arsênio Oswaldo (org.). Tenotã-Mõ: alertas sobre as conseqüências dos projetos hidrelétricos no rio Xingu. São Paulo: International Rivers Network, 2005. p. 281-295.

36. TEIXEIRA, Raquel Oliveira Santos; LASCHEFSKI, Andréa Luisa Zhouri; MOTTA, Luana Dias. Os estudos de impacto ambiental e a economia de visibilidades do desenvolvimento. Revista Brasileira de Ciências Sociais, São Paulo, v. 36, n. 105, p. 1-18, 2020.

37. VAINER, Carlos Bernardo. Conceito de "atingido": uma revisão do debate. In: ROTHMAN, Franklin Daniel. Vidas alagadas: conflitos socioambientais, licenciamento e barragens. Viçosa: UFV, 2008. p. 39-63.

38. VAINER, Carlos Bernardo.; ARAÚJO, Frederico Guilherme Bandeira de. Grandes projetos hidrelétricos e desenvolvimento regional. Rio de Janeiro: Cedi, 1992.

39. WCD. Dams and development: a new framework for decision-making. Londres: Routledge, 2000.

40. WINEMILLER, Kirk Owen et al. Balancing hydropower and biodiversity in the Amazon, Congo, and Mekong. Science, New York, v. 351, n. 6269, p. 128-129, 2016. 